\title{
Trinidad Chávez o la tradición liberal versión Janis Joplin
}

\author{
Guillermo Núñez Noriega*
}

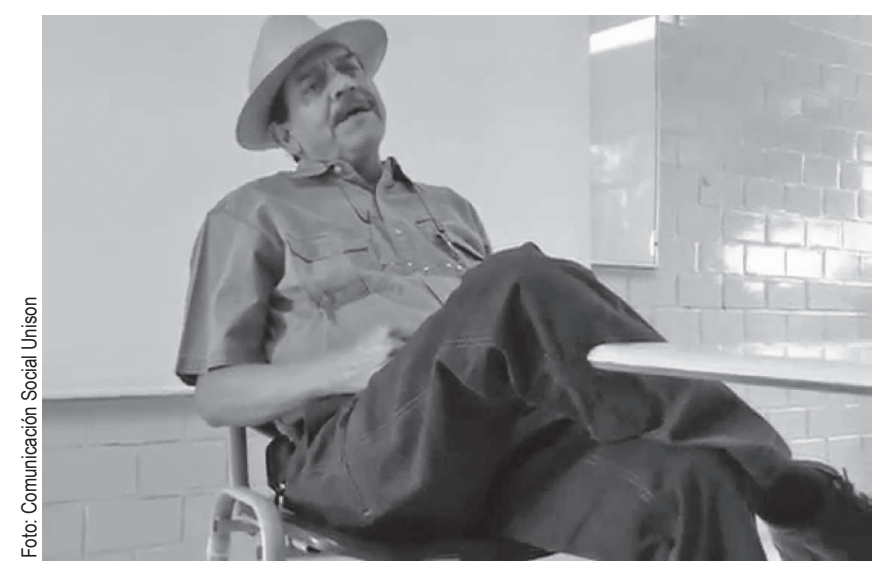

Estoy muy agradecido por haber sido invitado a participar en el homenaje que con motivo de la jubilación del maestro Trinidad Chávez Ortiz organizó el Departamento de Sociología y Administración Pública, el que con todos los claroscuros que justamente se le puedan señalar, ha acogido las esperanzas e inquietudes de muchos estudiantes, incluidas las mías, en nuestro agreste territorio sonorense, agreste geográficamente e ideológicamente.

Eran los años ochenta: mientras en la sociedad se imponía una especia de anti-intelectualismo neoliberal, en la universidad se respondía con ese lenguaje de chatarra y fierro viejo llamado marxismo ortodoxo. La Ilegada de Trinidad Chávez al Departamento de Sociología y Administración Pública marcó el inicio de un cambio paradigmático en el proceso formativo de las y los estudiantes de sociología, un cambio que hasta

\footnotetext{
* Investigador Titular D, y SNI Nivel II, Centro de Investigación en Alimentación y Desarrollo, A.C., gnunez@ciad.mx
}

la fecha, me parece, ha dado los mejores frutos en sus egresados. Trinidad abrió la ventana del aula para que entraran los aires de un nuevo paradigma epistemológico: el construccionismo social y el enfoque semiótico para el estudio de la cultura. Al hacerlo, también nos abrió a los estudiantes otra ventana: la de la utilidad del pensamiento social.

Pero las clases del maestro Trinidad Chávez, hay que decirlo, no solo se alejaban de la retórica conceptual anquilosada del marxismo soviético, también se alejaban de esa postura autoritaria, evangelizante como sermón dictado desde el Palacio de Invierno. Trinidad Chávez no adoctrinaba, enseñaba: mostraba nuevas maneras de entender y pensar la realidad, despertaba la imaginación. Sus clases eran pausadas, afables, serenas, profundas. Cuando se salía de ellas, uno sentía que tenía ante sí, un mundo por conocer. Su cátedra entusiasmaba y nos permitía ponernos en contacto con la razón profunda, tal vez incluso inconsciente para nosotros mismos, de por qué estudiábamos sociología. Las clases del maestro "Trini" no eran de ética, pero enseñaba ética, no eran de política, pero enseñaban que la forma más radical de la política era aprender a pensar el mundo de otra manera.

Trinidad Chávez, quiero decirlo con profundo agradecimiento y humildad, fue un maestro esencial en mi formación profesional y por lo tanto en mi vida. No puedo entender mi trayectoria académica sin él: mi tesis Sexo entre varones. Poder y resistencia en el campo sexual, mi interés en los métodos cualitativos, mi posterior formación como antropólogo. A él, a su trabajo como mentor, a sus clases, a su inspiración le debo mucho de lo que ahora soy como sociólogo y antropólogo. Gracias, maestro. Es cierto, Trinidad no tiene nada que ver con mi precisa/imprecisa y revolucionaria manera de entender la sexualidad o el género, o para este caso, con asumirla y vivirla, pero sí y mucho, de haber creado

\section{Savia}




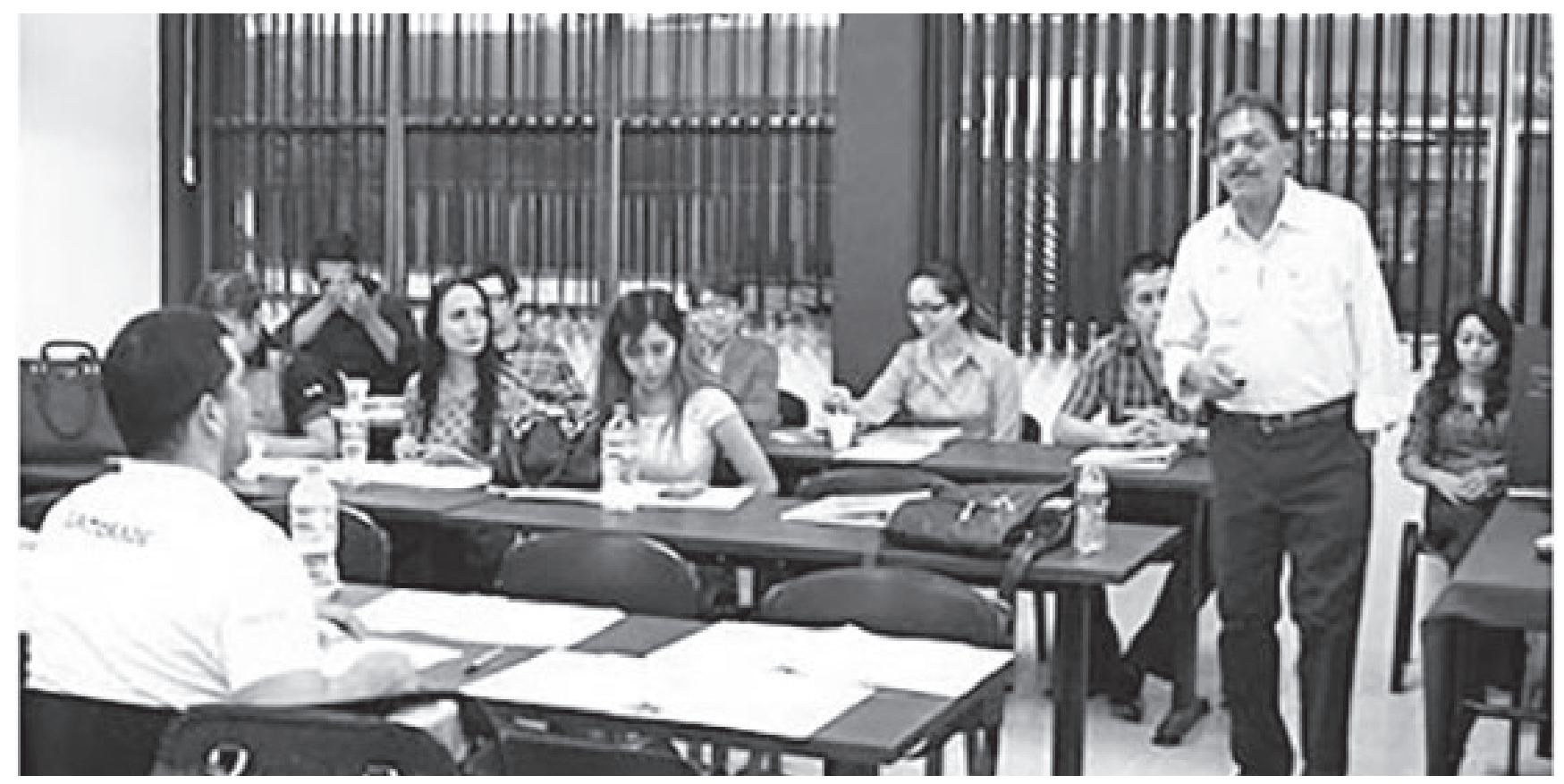

las condiciones, los cauces académicos y humanos para que esas inquietudes fueran adquiriendo el rigor teórico y metodológico que ameritaba una investigación científica.

Quiero contarles una anécdota: cuando llegada la oportunidad tuve que elegir mi tema de tesis, yo pensé originalmente en el tiempo libre de la clase obrera. Tuvieron que pasar dos semanas para entender que lo que realmente quería estudiar era la vida sexual que en su tiempo libre tenían los obreros. Trinidad era el maestro del taller de investigación. Con un profundo respeto y atención escuchó mi cambio de tema. Con el mismo respeto me dijo: "Guillermo, me parece que tu tema es muy importante e interesante, yo no sé nada del tema, pero estoy dispuesto a acompañarte en la investigación y a aprender contigo". Cuando recuerdo esas palabras, no puedo menos que pensar que en ellas se actualizaba la más bella tradición liberal y laica que fundó la universidad pública.

$Y$ es que si hiciéramos un estudio del habitus del profesor Trinidad Chávez, encontraríamos las voces sedimentadas de la llustración y la Revolución Francesa, los liberales mexicanos del XIX, los hermanos Flores Magón (que por cierto, sembraron muy buena semilla en el Sinaloa de donde es originario el maestro), los movimientos a favor de la autonomía universitaria, pero también el movimiento estudiantil del 68 y su clara rebeldía al estatus quo, al autoritarismo dentro y fuera del aula, y la esperanza de que una sociedad más justa, más humana y fraterna, es posible. Encontraríamos las voces de la tradición antropológica y su renuncia al etnocentrismo y su vocación de escuchar lo que los sujetos tienen que decir, en sus propios términos.

Estoy seguro que también encontraríamos un poquito de Janis Joplin, y estos versos de su canción Summertime que, intuyo, han dado forma al habitus pedagógico del maestro Trinidad Chávez:
One of these mornings

you're gonna rise, rise up singing, you're gonna spread your wings, child, and take, take to the sky, lord, the sky

Una de estas mañanas te vas a levantar, te vas a levantar cantando vas a desplegar tus alas, hijo, y vas a volar, volar hacia el cielo sí, señor, al cielo

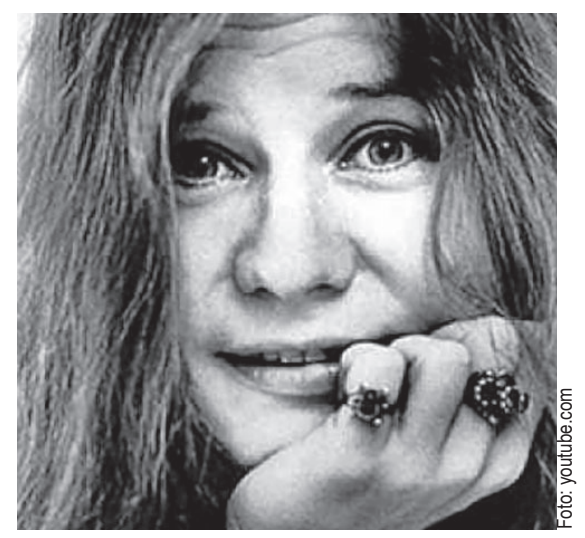

Gracias, maestro Trinidad Chávez, gracias por tu dedicación a la docencia, por tus horas de trabajo, gracias por ayudarnos a levantarnos, a levantar las alas y volar al cielo. Puedes estar seguro que tu vida está ya plenamente justificada y ojalá que eso no se te olvide nunca.

Con cariño 